\title{
Cultural Characteristics and Their Connection to Increased Risk of Software Project Failure
}

\author{
Magne Jørgensen ${ }^{1 *}$, Aiko Yamashita ${ }^{2 *}$ \\ ${ }^{1}$ Simula Research Laboratory, Fornebu, Norway. \\ ${ }^{2}$ Oslo and Akershus University, Oslo, Norway. \\ * Corresponding author. Email: magnej@simula.no; aiko.fallas@gmail.com \\ Manuscript submitted January 7, 2016; accepted April 1, 2016. \\ doi:10.17706/jsw.11.6.606-614
}

\begin{abstract}
Offshoring software projects have been documented to increase the risk of project failure. In particular, the cultural differences between software client and provider countries are believed to increase the risk of project failure. We analyze a large data set of small software projects with providers and clients from various countries. For each provider and client country, and each combination of provider and client country, we calculate the project failure rate. We use Hofstede's culture dimensions power distance, individualism, masculinity and uncertainty avoidance together with Hall's communication style to measure cultural characteristics and differences. We found a statistically significant increase in failure rate with increased difference in the provider and client country's communication style, but no connection between cultural differences and project failure rate using Hofstede's cultural characteristics. Provider countries, and in particular, client countries with a low-context communication culture had lower proportions of project failures than countries with high-context cultures. A decrease in power distance and increase in individualism were both connected with a decrease in project failure rate. In total, the cultural differences between countries seem to matter less than cultural characteristics of the countries. In particular, some of the cultural characteristics of the client country were strongly connected with project failure rates. Software offshoring clients may benefit from an awareness of the importance of their role in avoiding project failures and consider adopting the cultural characteristics of the most successful client offshoring countries. They may also benefit from selecting software providers from low-context cultures.
\end{abstract}

Key words: Software engineering, project failure, offshoring, culture, Hofstede's cultural dimensions, high vs. low context cultures.

\section{Introduction}

Many software projects are aborted or deliver products with unsatisfactory quality. The proportion of aborted projects is reported to be $9 \%$ [1], 11\% [2], and 11.5\% [3]. If we include the projects completed with a very poor product or process quality in our definition of project failure, the failure rate further increases, e.g., to $26 \%$ as in [3]. Factors potentially causing project failures include staff turnover, lack of team communication, lack of required technical and business knowledge, lack of motivation, team conflicts, lack of top management support, organizational politics, stability of organizational environment, changes in organizational priorities, original set of requirements is miscommunicated, continually changing system requirements, unclear system requirements, lack of project management know-how, poor planning of schedules and budget, poor change controls, failure to consider all costs, lack of adequate user involvement, 
failure to gain user commitment, failure to manage end-user expectations, conflicts between user departments, project complexity, difficulties with integration, large number of links to other systems, processes being automated are complex, and inadequate understanding of new technology [4]. Many of the listed project challenges, such as poor communication, may increase in relevance with increased cultural differences between the client and provider or be connected with cultural characteristics of the client or the provider, as illustrated by the following studies.

Nicholson and Sahay [5] reported from a software development company in England that failed to deal with the unclear boundaries between home and work life of their partner India, and the Indian employees' reluctance to confrontations. The English employees' beliefs in how to enable creative thinking differed a great deal from those of the Indian employees', which in turn led to considerable frustration on both sides. The lack of awareness of the non-explicit cultural differences, which is an example of so-called embedded knowledge, led to disasters in the collaboration between the English and the Indian company.

Krishna and Sahay [6] describe a software development collaboration between an Indian and Japanese company, where the Japanese company took much longer to reply to an email as compared to what would be common in India. The Indian company considered the delay as the onset of a problem. However, email delays were not seen as problem in the Japanese company, since an email would not be replied to until all the requests of the email were addressed. Another challenge was that the employees of the Japanese company preferred verbal, face-to-face communication, unlike the employees of the Indian company. The lack of understanding of these cultural differences led to communication problems and project delays.

Tsoukas [7] found that social practices, rooted in cultural values, hosted non-articulated knowledge that was taken for granted. The lack of awareness of the non-articulated knowledge led to misunderstandings and delivery failures when the unarticulated knowledge was not shared between the collaborating parties.

A survey conducted by the Vantage partners [8] reported on how much cultural differences impacted scope management. Out of those respondents who believed cultural differences had a substantial impact on scope management, 56\% reported significant cultural challenges related to directness of communication, $59 \%$ to making commitments, and 50\% to dealing with conflicts. The survey found that ineffective execution of scope management and other critical outsourcing activities, as a result of cultural differences and challenges, impacted the clients and providers in terms of low staff morale, missed deadlines, poor quality and low end-user satisfaction.

A survey by Kvedaraviciene and Boguslauskas [9], with participants from Finland, Sweden, Lithuania, the Czech Republic, Slovakia and Denmark, reported that the two most important cultural criteria in the selection of an outsourcing partner were cultural compatibility and internationalization. The authors argue that the importance of cultural differences is underestimated in current models for country selection for outsourcing purposes.

Winkler, Dibbern, and Heinzl [10] found that cultural differences may affect the client-provider relationship quality in terms of trust, provider performance, cooperation and constructive confrontation-all of which are important qualities for a successful offshore project.

The above studies suggest that cultural differences, and to some extent cultural characteristics, increase the risk of software project failures. The above studies are, as far as we are aware, representative of the studies on the effect of culture on software offshoring projects. We have been unable to find any empirical studies identifying the size of the effect of cultural differences or cultural characteristics on large datasets of software development projects. This is a goal of the study reported in this paper.

The paper is organized as follows: Section II describes the design of the study, Section III presents the results, Section IV discusses the results and the limitations, and Section V provides the conclusions.

\section{Design of the Study}


The dataset we used to analyze the effect of culture consists of small-scale software projects completed between 2001 and 2012. The clients and providers of the software projects used the services of a web-based marketplace that connected software clients and providers. The providers were typically single software developers or smaller outsourcing companies located in low-cost countries, but include developers and companies from high-cost countries, as well. In $90 \%$ of the projects, the client and provider were located in different countries. The price range of projects was from 1-30,000 USD, with a mean of 146 USD, i.e., most projects were very small and may be characterized as tasks rather than projects. Nearly all projects were based on a fixed-price contract between the client and the provider.

The information we use about each project is:

- Whether a started project was cancelled or not

- The client's satisfaction with the provider's performances

- The country of the client

- The country of the provider

We defined a project as failed if the project had been cancelled or the provider received a client satisfaction rating of "poor" or worse. For the purpose of the analysis of cultural differences between countries and failure rate, we include only combinations of client and provider countries where there were at least 100 projects. This was the case for 127 combinations of client and provider countries representing about 81,000 projects. For the analysis of the connection between cultural characteristics of a client or a provider country and the country's failure rate we include countries with at least 100 projects. This was the case for 49 client countries (about 109,000 projects) and for 68 provider countries (about 110,000 projects).

Hofstede identified cultural dimensions across countries by surveying IBM employees in over 50 countries [11]. In our study, we use four of Hofstede's culture dimensions, as follows: power distance (pdi), individualism (idv), masculinity (mas) and uncertainty avoidance (ua). The dimensions may be described as (descriptions taken from geert-hofstede.com/national-culture.html):

- Power distance: Expresses the degree to which the less powerful members of a society accept and expect that power is distributed unequally. The fundamental issue here is how a society handles inequalities among people. People in societies exhibiting a large degree of Power Distance accept a hierarchical order in which everybody has a place and which needs no further justification. In societies with low Power Distance, people strive to equalize the distribution of power and demand justification for inequalities of power.

- Individualism vs. collectivism: The high side of this dimension, called individualism, can be defined as a preference for a loosely-knit social framework in which individuals are expected to take care of only themselves and their immediate families. Its opposite, collectivism, represents a preference for a tightlyknit framework in society in which individuals can expect their relatives or members of a particular ingroup to look after them in exchange for unquestioning loyalty. A society's position on this dimension is reflected in whether people's self-image is defined in terms of "I" or "we."

- Masculinity vs. femininity: The Masculinity side of this dimension represents a preference in society for achievement, heroism, assertiveness and material rewards for success. Society at large is more competitive. Its opposite, femininity, stands for a preference for cooperation, modesty, caring for the weak and quality of life. Society at large is more consensus-oriented. In the business context, Masculinity versus Femininity is sometimes also related to as "tough versus tender" cultures.

- Uncertainty avoidance: The Uncertainty Avoidance dimension expresses the degree to which the members of a society feel uncomfortable with uncertainty and ambiguity. The fundamental issue here is how a society deals with the fact that the future can never be known: should we try to control the future or just let it happen? Countries exhibiting strong Uncertainty Avoidance maintain rigid codes of belief 
and behavior and are intolerant of unorthodox behavior and ideas. Weak Uncertainty Avoidance societies maintain a more relaxed attitude in which practice counts more than principles.

A country is given a score for each cultural dimension, with a value from 0 to 100 . We use the difference in the score between two countries for a cultural dimension as an indication of the difference in culture for the relevant dimensions. We do not claim that this accurately reflects the cultural difference for that dimension, as this would, require that we give a precise and commonly accepted definition of concepts such as individualism and masculinity. The only assumption we make for analysis is that the difference between Hofstede's value tends to be connected with what we normally would agree on as a difference between the cultural dimension we analyze, e.g., that the USA's much higher score on individualism than India's (100 vs. 49) reflects that the USA has a substantially more individualistic culture than India.

We use Hofstede's own assessments about how each of the countries' scores on each of these factors (taken from geert-hofstede.com/national-culture.html). The cultural difference between two countries $\mathrm{i}$ and $\mathrm{j}$ on a factor (pdi_diff, idv_diff, mas_diff, us_diff) is defined as the square of the difference between the two countries' score on that factor:

- $\quad$ di_diff $f_{i j}=\left(p d i_{i}-p d i_{j}\right)^{2}$

- $\quad i d v_{-} d i f f_{i j}=\left(i d v_{i}-i d v_{j}\right)^{2}$

- mas $_{-}$diff $f_{i j}=\left(m a s_{i}-m a s_{j}\right)^{2}$

- $u s_{-}$diff $f_{i j}=\left(u s_{i}-u s_{j}\right)^{2}$

The total cultural difference (Diff_tot) between two countries $i$ and $j$ is defined as the sum of the squared difference for the four cultural factors:

- $\quad$ Diff_tot $_{i j}=p d i_{-} d i f f_{i j}+i d v_{-} d i f f_{i j}+$ mas_diff $_{i j}+u s_{-} \operatorname{diff}_{i j}$

As our measure of to what degree a country has a high or low-context culture, we use the work of Hall [12]. In a higher-context culture, less of the context is communicated and more is left unsaid or is implicit in the context. In a lower-context culture, on the other hand, the communication is more explicit and includes more of the context. Hall [12] describes the differences between high and low-context communication, present in high and low-context cultures, as: A high context communication or message is one in which most of the information is already in the person, while very little is in the coded, explicit, transmitted part of the message. A low context communication is just the opposite, i.e., the mass of the information is vested in the explicit code. Accordingly, a culture relying more on high context communication is termed a high context and a culture relying more on low context communication, a low context culture.

We use the assessment of countries as either a high or low-context culture found in [13], where each country is given a category number from 1 (low context culture) to 5 (high context culture). The difference between a client country $\mathrm{i}$ and a provider country $\mathrm{j}$ on low/high-context (context_diff) is calculated as the square of the difference between the two countries in the high/low-context cultural factor:

- context_diff $_{i j}=\left(\text { context_cat }_{i}-\text { context_cat }_{j}\right)^{2}$

Our general hypotheses, applied for each of the described measures of culture and cultural differences, are as follows:

H1: A higher cultural difference between a client and a provider country is correlated with higher project failure rate.

H2: The cultural factors of the provider country are correlated with the project failure rate. 
H3: The cultural factors of the client country are correlated with the project failure rate.

\section{Results}

\subsection{Cultural Difference between Client and Provider Country}

We found no significant correlations between the differences for the four evaluated Hofstede's cultural dimensions and project failure rate (see Fig. 1), or between the total cultural difference and the project failure rate (see Fig. 2). The correlations with project failure rate were $-0.12(p=0.2)$ for pdi_diff, $-0.09(p=0.3)$ for idv_diff, $0.13(\mathrm{p}=0.2)$ for mas_diff, $-0.14(\mathrm{p}=0.1)$ for ui_diff and $-0.12(\mathrm{p}=0.2)$ for diff_tot.

As can be seen in Fig. 1, with the exception of the cultural difference for the masculinity factor, there is a weak negative correlation suggesting that larger cultural differences are correlated with fewer rather than with more project failures when using Hofstede's cultural dimensions. Using a rank correlation did not change these, to some extent, surprising results.
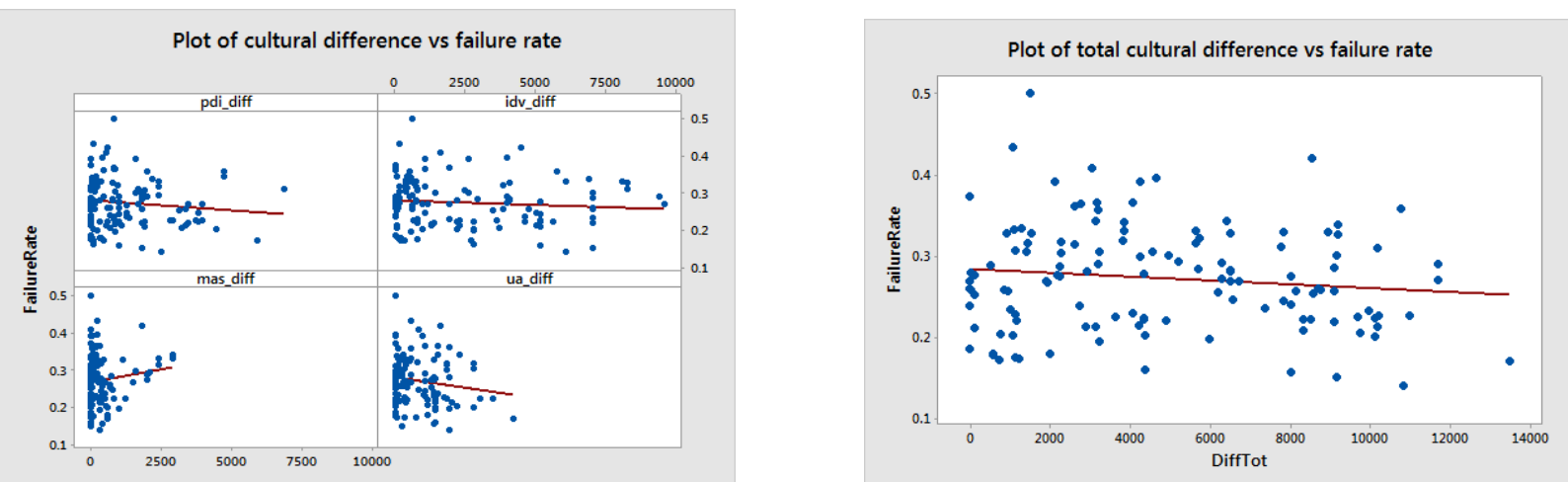

Fig. 1. Analysis of difference for each of Hofstede's dimensions. Fig. 2. Analysis of total difference using Hofstede's dimensions.
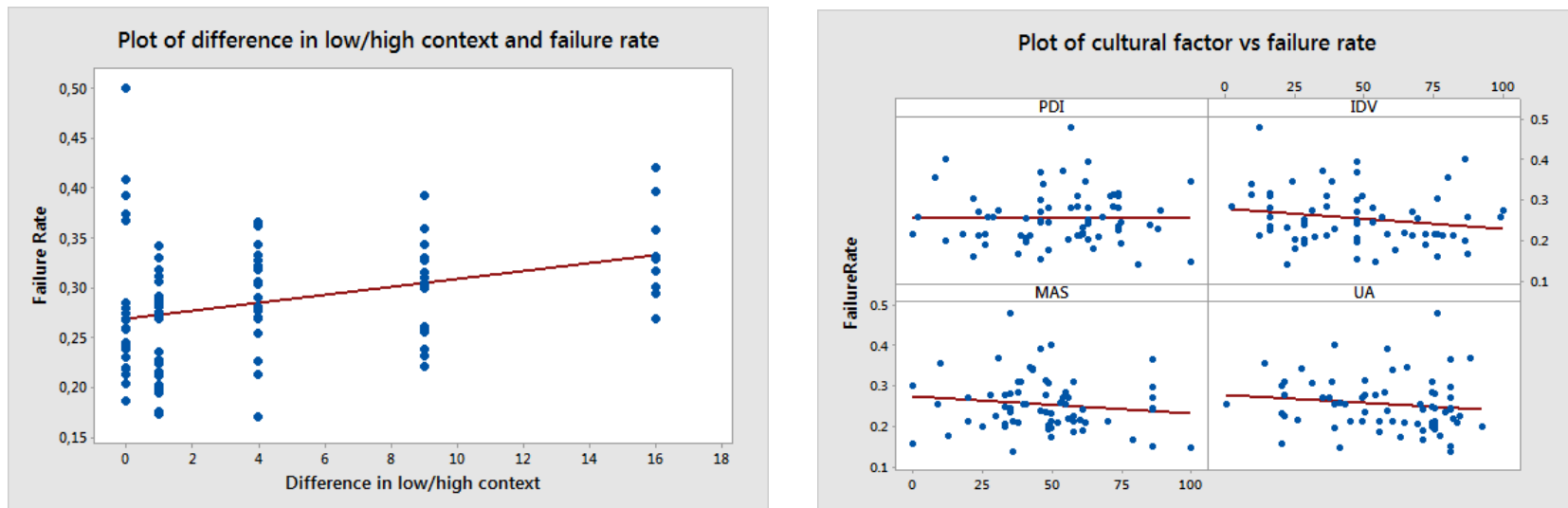

Fig. 3. Analysis of difference in communication style. Fig. 4. Analysis of Hofstede's dimensions of provider countries.

The connection between cultural difference and failure rate using Hall's concept of low vs. high-context culture gave, on the other hand, a statistically significant, medium strong correlation $0.33(\mathrm{p}<0.01)$, see Fig. 3 .

In total, the results suggest that cultural difference in communication style (high vs. low context cultures) has an effect on project failure, but not the differences related to Hofstede's cultural dimensions.

\subsection{Cultural Characteristics of Provider Country}


The correlations between Hofstede's culture dimensions of the provider country and the failure rate were $0.01(p=0.9)$ for pdi, $-0.19(p=0.1)$ for idv, $-0.13(p=0.3)$ for mas and $-0.14(p=0.3)$ for ua. Fig. 4 displays the data. The strongest correlation, not statistically significant, was between the level of individualism and failure rate, suggesting that provider countries that are higher on independence may have slightly lower failure rates.

The correlation between the communication style (high/low context) for provider countries and project failure rate was medium strong $(0.37)$ and statistically significant $(p=0.02)$, suggesting that communication style (as in the analysis of the cultural differences) is an important factor in understanding why some offshoring projects fail. Fig. 5 displays the data.

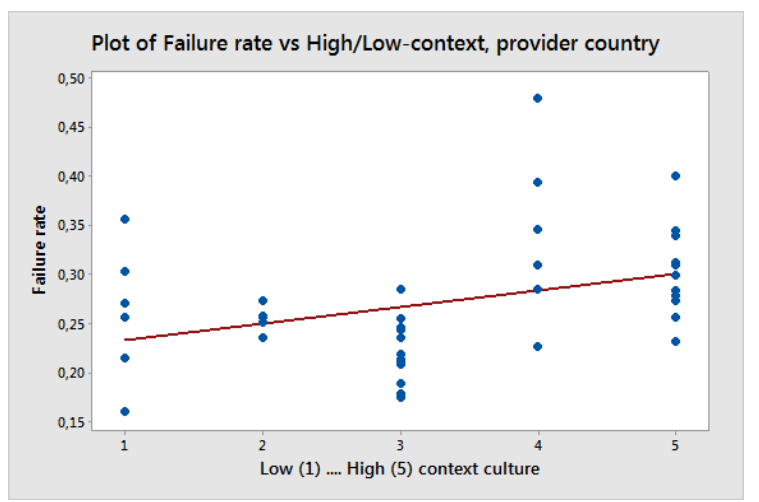

Fig. 5. Analysis of communication style of provider countries.

\subsection{Cultural Characteristics of Client Country}

The correlations between the culture factors of the provider country and the failure rate were $0.39(p<0.01)$ for pdi, $-0.50(p<0.01)$ for idv, 0.24 ( $p=0.1)$ for mas and $0.13(p=0.4)$ for ua. Fig. 6 displays the data. As can be seen, there are interesting, statistically significant correlations between the power distance and the failure rate and between the level of individualism and the failure rate. Client countries with a low level of power distance and high level of independence have lower failure rates.

The correlation between the high/low-context culture for client countries and the project failure rate was as strong as $0.59(p<0.01)$. Fig. 7 displays the data. The strength of the correlation, which was even stronger than that for the provider countries, suggests that communication style is of substantial interest when trying to understand factors leading to project failures.

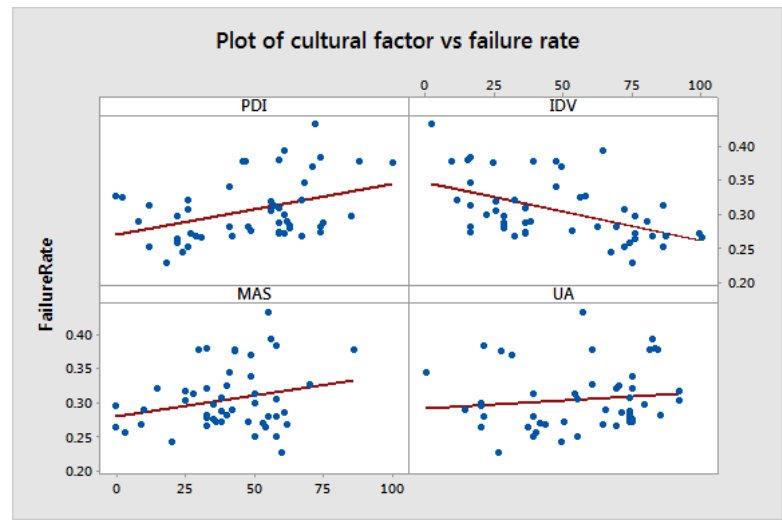

Fig. 6. Analysis of Hofstede's dimensions of client countries.

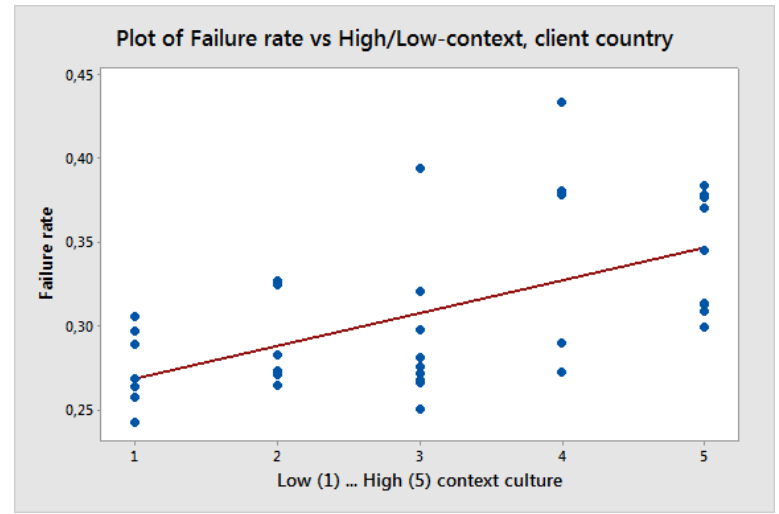

Fig. 7. Analysis of communication style of client countries.

\section{Discussion and Limitations}


Our analyses show that cultural differences between the provider and client countries, applying Hofstede's four cultural dimensions power distance, individualism, masculinity and uncertainty avoidance, were not significantly correlated with project failure. An increased difference in communication style, as measured by Hall's concept of high vs. low context cultures, was, on the other hand, significantly connected with higher failure rate. It seems, consequently, that the cultural concept of communication style touches upon a central element in successful software project collaborations. This was supported by the findings that countries with a low-context culture had substantially lower failure than those with a high-context culture. While the client countries with a low-context culture had an average failure rate of $27 \%$, those with a high-context culture had an average failure rate of $35 \%$.

While the cultural difference between the client and the provider country may have some influence on the project failure rate, our analyses suggest that it is rather the cultural characteristics of the provider and, even more, the client country that matters. As an illustration, when providers from India (a high-context culture) have clients from India, there is a high degree of cultural similarity (although there clearly may be cultural differences related to differences in professions and within India). If the cultural differences were of highest importance, we should expect a reduced failure rate compared to when the client was from outside India, from countries with substantially different cultures. The opposite was the case, with a $16 \%$ increase in failure rate when both the client and the provider were from India compared to when the client was from outside India.

Especially interesting for the importance of cultural characteristics is how much a low level of power distance, a high degree of individualism and a low-context culture are connected with a lower proportion of project failure. The correlation between communication style and project failure rate was, for example, as high as $59 \%$.

Our results can be considered to extend the findings reported in [10]. In that study the authors found that cultural differences in terms of power distance negatively influenced the likelihood of offshore outsourcing success. The main difference with our results is that [10] emphasizes the difference in power distance, while we find that it is the power distance of the client country that is most strongly connected with software project problems.

Roebuck et al. [14] found that the national culture is a primary determinant of communication behaviors, in particular with respect to listening. Listeners from high-context cultures, such as India and Malaysia, are more likely to respond to their gut-level reaction (the implicit message) than to the actual facts in the message. People from low-context cultures such as the USA are, on the other hand, more likely to provide explicit, verbal communication. The authors argue that managers who listen effectively benefit not only their employees but also all stakeholders within and outside an organization. Moreover, Roebuck et al. [14] state that: as organizational structures become flatter (i.e., decreased power distance) managerial roles will focus more on coaching and collaboration, activities in which listening skills will be essential to achieving individual, team, and organizational goals hinting that communication skills manifested in low-context cultures, and lower power distance come hand-in-hand, and they can decrease the risks of project failure. This supports our finding that good client countries were low on power distance, high on individualism and using a low-context communication style.

There are many reasons for project failure and, clearly, many of them are not related to cultural differences or cultural characteristics of provider or client countries. This means that even when we have strong correlations, we cannot expect to explain more than a small share of the reasons for project failure. As an illustration, even if the correlation between communication style and project failure rate for client countries is high (59\%), the increase in the project failure rate between those in the low-context countries and those in the high-context countries was only an increase from 0.27 to 0.34 . 
Our study is a correlational study, and it is difficult to document a causal relationship between the studied cultural dimensions and project failure based on our analyses. It may instead be that the studied cultural dimensions are correlated with underlying, real causes of project failure, and that our results merely point to indicators of project failure. The finding that the communication style, i.e., the inclusion of more or less context in the communication, was the strongest indicator of project failure may however point at a core reason for software project failure. If the client is unable to communicate clearly his/her expectations and expect the provider to understand this from the context, there may easily be misunderstandings and, consequently, a failed project. The case studies in Section I support this interpretation.

The measures of the cultural concepts, especially those of Hofstede, have been much criticized and it is not clear how well they measure what they intend to measure. In addition, there will be large differences within a country, such as India, regarding culture. In spite of these limitations, it is believed that the measures are connected with some core cultural aspects of the analyzed countries, e.g., that the hierarchies and communication style are indeed different in India and the USA, and to some extent represented by the measured cultural dimensions.

Correlational analyses assume linear relationships. The real connection may not be linear and other analyses models may give better results.

Finally, the projects in our analyses are quite small, collected from an online marketplace and not necessarily representative of other types of larger software projects with, perhaps, more professional companies on the client and/or provider side. More studies should be conducted to examine how representative our results are for other types of projects.

\section{Conclusions}

Our results confirm previous findings on the importance of cultural factors when offshoring software development. As opposed to most previous work, we find that it is not the difference in culture between the client and the provider countries that is the key to understanding project failure, but rather the cultural characteristics of the provider, and in particular, the client countries themselves. We find that the communication style, i.e., whether a country has a low or high-context communication culture, is the factor most connected with project failure. A low-context culture, which tends to include more context information in the communication, is connected with substantially less project failure both for the client and the provider. In addition, we found that a client culture with low power distance and high individualism was less likely to experience a project failure.

Our results suggest that software offshoring clients may benefit from being more aware of the importance of their role in avoiding project failures and adopting the cultural characteristics of the most successful client offshoring countries. They may, for example, given that they are not already scoring well on these aspects, try to improve on communicating more of the context, reduce the power distance in their own organization, and encourage individualism among their employees. The clients may, we think, also reduce the risk of project failure when selecting software providers from low-context rather than high-context communication cultures.

\section{Acknowledgement}

The work has been funded by RFF (Regional Research Funds) of Norway and is part of the SMIOS-project.

\section{References}

[1] Sauer, C., Gemino A., \& Reich, B. H. (2007). The impact of size and volatility on IT project performance. Communications of the ACM, 50(11), 79-84.

[2] Tichy, L., \& T. Bascom (2008). The business end of IT project failure. Mortgage Banking, 68(6), 28.

[3] Emam, K. E., \& Koru, A. G. (2008). A replicated survey of IT software project failures. IEEE Software, 
25(5), 84-90.

[4] Nakatsu, R. T., \& Iacovou, C. L. (2009). A comparative study of important risk factors involved in offshore and domestic outsourcing of software development projects: A two-panel Delphi study. Information and Management, 46(1), 57-68.

[5] Nicholson, B., \& Sahay S. (2004). Embedded knowledge and offshore software development. Information and Organization, 14(4), 329-365.

[6] Krishna, S., \& Sahay S. (2001). Global Software Outsourcing Experiences in Korea and Japan: Some Preliminary Investigations. University of Pennsylvania: New Delhi, India.

[7] Tsoukas, H. (1996). The firm as a distributed knowledge system: A constructionist approach. Strategic Management Journal, 17, 11-25.

[8] Ertel, D., Enlow S., \& Barr K. (2010). Managing outsourcing relationships: Governance in global deals. Vantage Partners.

[9] Kvedaraviciene, G., \& Boguslauskas, V. (2015). Underestimated importance of cultural differences in outsourcing arrangements. Engineering Economics, 21(2).

[10] Winkler, J. K., Dibbern J., \& Heinzl A., (2008). The impact of cultural differences in offshore outsourcing - Case study results from German-Indian application development projects. Information Systems Frontiers, 10(2), 243-258.

[11] Hofstede, G., (1980). Culture's Consequences: International Differences in Work-Related Values. Sage Publications, Inc.

[12] Hall, E. T., (1989). Beyond Culture. Anchor.

[13] Usunier, J.-C., \& Roulin N., (2010). The influence of high-and low-context communication styles on the design, content, and language of business-to-business web sites. Journal of Business Communication, 47(2), 189-227.

[14] Roebuck, D. B., et al. (2015). Comparing perceived listening behavior differences between managers and nonmanagers living in the United States, India, and Malaysia. International Journal of Business Communication, 1-34.

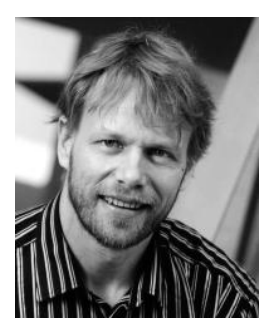

Magne Jørgensen is a chief research scientist at Simula Research Laboratory, a professor at University of Oslo, an advisor at Scienta and a guest professor at Kathmandu University. His research includes work on management of software projects, evidence-based software engineering and human judgment. He has published more than 70 papers on these and other topics in software engineering, forecasting, project management and psychology journals. He has been ranked the top scholar in systems and software engineering four times and was in 2014 given the ACM Sigsoft award for most influential paper the last ten years for his work on evidence-based software engineering.

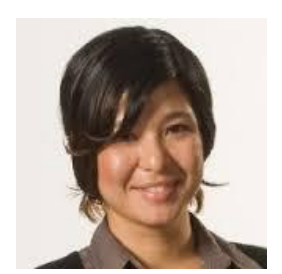

Aiko Yamashita received a BSc. degree from the Costa Rica Institute of Technology in 2004 and an MSc. degree from Göteborg University in 2007. In 2012, she finalized her doctoral degree at Simula Research Laboratory and the Department of Informatics, University of Oslo. Currently, she works as an entrepreneur and holds an Adjunct associate professorship at Oslo and Akershus University College of Applied Sciences, Norway. She has worked as a software engineer, consultant and advisor in Costa Rica, the USA, Sweden and Norway within diverse organizations. Her research interests include empirical software engineering, software evolution and quality, IT for sustainability and education, knowledge transfer, and innovation processes within IT. Aiko is an IEEE fellow and an active member of the IEEE Software Initiatives Team. 